\title{
Radical surgical resection of advanced thymoma and thymic carcinoma infiltrating the heart or great vessels with cardiopulmonary bypass support
}

\author{
Michael Ried ${ }^{1 *}$, Reiner Neu', Berthold Schalke², Marietta von Süßkind-Schwendi ${ }^{1}$, Zsolt Sziklavari ${ }^{3}$
} and Hans-Stefan Hofmann ${ }^{1,3}$

\begin{abstract}
Background: Radical surgical resection of advanced thymic tumors invading either the heart or great vessels facing towards the heart is uncommonly performed because of the potential morbidity and mortality. To achieve a complete tumor resection, the use of cardiolpulmonary bypass (CPB) support might be necessary.

Methods: Retrospective analysis of the results in six patients, who underwent radical tumor resection with CBP support.

Results: Mean age was 46 years (27 to 66 years) and five patients were male. Tumor infiltration of the heart or the great vessels was evident in all patients. Five patients underwent induction therapy. Two patients were operated in complete cardioplegic arrest (antegrade cerebral perfusion: $n=1$ ). Arterial cannulation of the ascending aorta $(n=5)$ or the femoral artery $(n=1)$ and venous cannulation of the right atrium $(n=4)$ or the femoral vein $(n=2)$ were performed. Resection of the left brachiocephalic vein $(n=6)$, resection of the superior caval vein $(n=2)$, the ascending aorta $(n=1)$ and the complete aortic arch with outgoing branches $(n=1)$ were performed. A macroscopic complete resection (R0/R1) was achieved in five patients, whereas one patient was resected incompletely (R2). In-hospital mortality was $0 \%$. Three (50\%) patients needed operative revision (hematothorax: $n=2$, chylothorax: $n=1$ ). All patients had a complicated postoperative course and developed respiratory insufficiency.
\end{abstract}

Conclusions: Locally advanced thymoma/thymic carcinoma invading the heart or great vessels can be treated with radical surgical resection alongside with increased perioperative morbidity. The usage of CBP improves the chance of complete tumor resection in selected patients and might lead to a prolonged survival.

Keywords: Thymoma, Thymic carcinoma, Cardiopulmonary bypass support, Radical surgical resection

\section{Background}

Complete surgical resection still builds the mainstay of treatment in all stages of thymoma and thymic carcinoma $[1,2]$. Its prognosis depends on the preoperative tumor stage, as classified by the Masaoka-Koga staging system describing the anatomical extend of

\footnotetext{
* Correspondence: micha.ried@t-online.de

Presented at the "23rd Annual Meeting of The German Society of Thoracic

Surgery" in Osnabrück, October 2014.

'Department of Thoracic Surgery, University Medical Center Regensburg,

Franz-Josef-Strauß-Allee 11, D-93053 Regensburg, Germany

Full list of author information is available at the end of the article
}

the mediastinal tumor, the World Health Organization (WHO) histological classification system and the completeness of surgical resection [3-5]. In particular, in Masaoka-Koga stage III tumors, defined by the macroscopic infiltration of neighbouring structures (i.e., mediastinal pleura, pericardium, lung tissue, and great vessels), and in stage IVa thymic tumors with pleural thymoma spread, a complete surgical resection is not always achievable [6-8]. A multimodality treatment regime consisting of chemotherapy, surgical resection and in some cases radiotherapy is recommended for advanced or primarily unresectable tumors $[9,10]$.

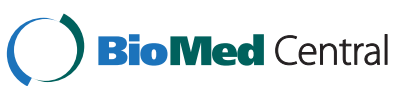

(c) 2015 Ried et al. Open Access This article is distributed under the terms of the Creative Commons Attribution 4.0 International License (http://creativecommons.org/licenses/by/4.0/), which permits unrestricted use, distribution, and reproduction in any medium, provided you give appropriate credit to the original author(s) and the source, provide a link to the Creative Commons license, and indicate if changes were made. The Creative Commons Public Domain Dedication waiver (http://creativecommons.org/publicdomain/zero/1.0/) applies to the data made available in this article, unless otherwise stated. 
However, in this rare surgical condition no common and standardized treatment regime exists yet and the optimal way of therapy remains controversial [11, 12]. Most patients presenting with thymoma/thymic carcinoma invading the heart or great vessels are not considered for surgical resection because of technical reasons, the potential perioperative morbidity and mortality, and the unknown probability of significant impact on survival [13]. Therefore, these operative procedures are uncommonly performed and there have been only some case reports of patients, who underwent extended surgical resection with extracorporeal circulation in order to achieve complete tumor resection [14-17]. In this report we describe our experience of radical surgical tumor resection with cardiopulmonary bypass (CPB) support in patients with locally advanced thymoma or thymic carcinoma invading either the heart or great vessels facing towards the heart.

\section{Methods}

This was an observational study. We reviewed the records of patients with advanced thymoma or thymic carcinoma, who received surgical resection with $\mathrm{CPB}$ support at the Department of Thoracic Surgery, University Medical Center Regensburg. Between November 2010 and October 2014 a total of six consecutive patients with locally advanced thymoma or thymic carcinoma Masaoka-Koga stage III and IVa with preoperative or intraoperative evidence of tumor infiltration of the heart, great vessels, or both, were included. Our Institutional Review Board waived the necessity of approval for the data report, because of using only routine patient data. All patients signed an informed consent form. Perioperative data and operative reports were obtained from the institutional database and medical records. Patients were recruited in an interdisciplinary thoracic oncology assessment involving thoracic surgeons, neurologists, oncologists, pulmonary specialists, radio-oncologists and radiologists. All perioperative complications regarding postoperative morbidity and mortality were documented.

All patients received a detailed preoperative history, physical examination, lung function testing and echocardiography to ensure functional operability. Preoperative staging included computed tomography (CT) scan of the chest in all patients. Cine magnetic resonance imaging (MRI) was performed to evaluate the extent of myocardial or great vessel invasion. The preoperative clinical and pathologic stage at the time of diagnosis was determined according Masaoka-Koga staging system [4, 18]. The pathologic results were classified according to the WHO histological classification system $[5,19]$.
Macroscopic complete surgical resection in a multimodality treatment setting was the aim in all patients. Induction therapy (chemotherapy or octreotid/prednisone) was administered in patients with large tumors, which were considered not completely resectable and in order to improve surgical resectability (partial remission: tumor reduction $\geq 50 \%$ ). Second-line treatments were administered when appropriate depending on tumor stage, histology and completeness of resection. In addition, adjuvant therapies were accomplished depending on the postoperative patient's status and significant postoperative comorbidity. A further reason for not performing adjuvant therapy was patient refusal.

\section{Results}

\section{Patient characteristics}

Patient characteristics and perioperative data are listed in Table 1 . The study comprised six patients who underwent surgical resection with CPB support of an invasive thymoma or thymic carcinoma that invaded the myocardium, the superior caval vein (SCV), the left brachiocephalic vein (LBV), the ascending aorta and/or the aortic arch (Figs. 1 and 2). Included were five men and one woman with a mean age at time of surgery of 46 years (range 27 to 66 years). There were two patients with proven myasthenia gravis with one being without symptoms since one year before the re-operation due to suspicious mediastinal recurrence of thymoma in a time interval of 26 months after previous transsternal radical thymoma (WHO type B2) resection.

After clinical and radiological staging the other five (83 \%) patients with first diagnosis of thymoma/thymic carcinoma received induction therapy with chemotherapy or octreotid/prednisone. Partial remission was documented in all patients and surgical resection was the next step as part of the multimodality treatment concept. Curative resection was the intention to treat in all patients except one patient with expected tumor debulking surgery because of suspicious thymoma invasion in the myocardium of the left ventricle and the main pulmonary artery.

\section{Operative data}

$\mathrm{CPB}$ was necessary in all patients to ensure a complete tumor resection as possible, to relieve the heart for better operability and to stabilize the hemodynamics during preparation. Furthermore, the decision for CPB support was made intraoperatively for safety reasons and for better tumor preparation. Except for one patient (femoral artery), the ascending aorta was cannulated. The venous cannulation was performed either in the right atrium $(n=4)$ or via the femoral vein $(n=2)$, depending on the central tumor invasion in the SCV or the right atrium. Heparin $(350 \mathrm{IE} / \mathrm{kg})$ was administered and 
Table 1 Demographic and perioperative data

\begin{tabular}{|c|c|c|c|c|c|c|c|}
\hline $\mathrm{Pt}$ & $\begin{array}{l}\text { Age [years]/ } \\
\text { Sex/MG }\end{array}$ & $\begin{array}{l}\text { Masaoka-Koga } \\
{[3,4] / \mathrm{WHO}[5]}\end{array}$ & Induction therapy & Cannulation & $\begin{array}{l}\text { Surgical approach: structures } \\
\text { resected }\end{array}$ & $\begin{array}{l}\text { CPB-/OP-time } \\
\text { [min] }\end{array}$ & $\begin{array}{l}\text { ICU-stay } \\
\text { [days] }\end{array}$ \\
\hline 1 & $66 / \mathrm{m} /$ none & III/A & Octreotid/prednisone & $\begin{array}{l}\text { Ascending aorta/femoral } \\
\text { vein }\end{array}$ & $\begin{array}{l}\text { Sternotomy: SCV, LBV, } \\
\text { pericardium }\end{array}$ & $94 / 269$ & 28 \\
\hline 2 & $27 / \mathrm{m} /$ none & IVa (left)/B3 & $\begin{array}{l}\text { PAC; octreotid/ } \\
\text { prednisone }\end{array}$ & Ascending aorta/RA & $\begin{array}{l}\text { Sternotomy, left hemi } \\
\text { clamshell thoracotomy: LBV, } \\
\text { pericardium, left pleurectomy, } \\
\text { left upper lobe }\end{array}$ & $152 / 539$ & 5 \\
\hline 3 & $61 / \mathrm{m} /$ none & III/C & PAC & $\begin{array}{l}\text { Femoral artery/femoral } \\
\text { vein }\end{array}$ & $\begin{array}{l}\text { Sternotomy: Chest wall, left } \\
\text { upper lobe, pericardium, } \\
\text { LBV, tumor debulking aortic } \\
\text { arch and main pulmonary } \\
\text { artery }\end{array}$ & $378 / 664$ & 28 \\
\hline 4 & 35/f/MG & IVa (right)/B3 & $\begin{array}{l}\text { PAC; octreotid/ } \\
\text { prednisone }\end{array}$ & Ascending aorta/RA & $\begin{array}{l}\text { Sternotomy, right hemi } \\
\text { clamshell thoracotomy: } \\
\text { EPP, pericardium, LBV }\end{array}$ & $177 / 393$ & 13 \\
\hline 5 & $48 / \mathrm{m} /$ none & III/C & PAC & $\begin{array}{l}\text { Ascending aorta/RA } \\
\text { (hypothermic circulatory } \\
\text { arrest) }\end{array}$ & $\begin{array}{l}\text { Sternotomy: LBV, pericardium, } \\
\text { aortic arch, brachiocephalic } \\
\text { trunk, left carotid artery, left } \\
\text { subclavian artery, wedge } \\
\text { resections right and left lungs }\end{array}$ & $240(42) / 467$ & 26 \\
\hline 6 & $41 / \mathrm{m} / \mathrm{MG}$ & III/B2 & None & Ascending aorta/RA & $\begin{array}{l}\text { Sternotomy: LBV, ascending } \\
\text { aorta }\end{array}$ & $121 / 265$ & 15 \\
\hline
\end{tabular}

$C P B$ cardiopulmonary bypass, EPP extrapleural pneumonectomy, $f$ female, $L B V$ left brachiocephalic vein, $m$ male, $M G$ myasthenia gravis, $O P$ operation, $P A C$ cisplatin, doxorubicin, cyclophosphamid, Pt patient, RA right atrium, SCV superior caval vein, WHO World Health Organication

CPB was performed with mild to moderate hypothermia (34 to $28^{\circ} \mathrm{C}$ ), except for one patient in whom hypothermic circulatory arrest $\left(18^{\circ} \mathrm{C}\right)$ was required for complete reconstruction of the aortic arch. Cardioplegic cardiac arrest was necessary in two patients who underwent aortic surgery.

The surgical procedure was preferably a radical tumor resection in all patients including the en bloc resection

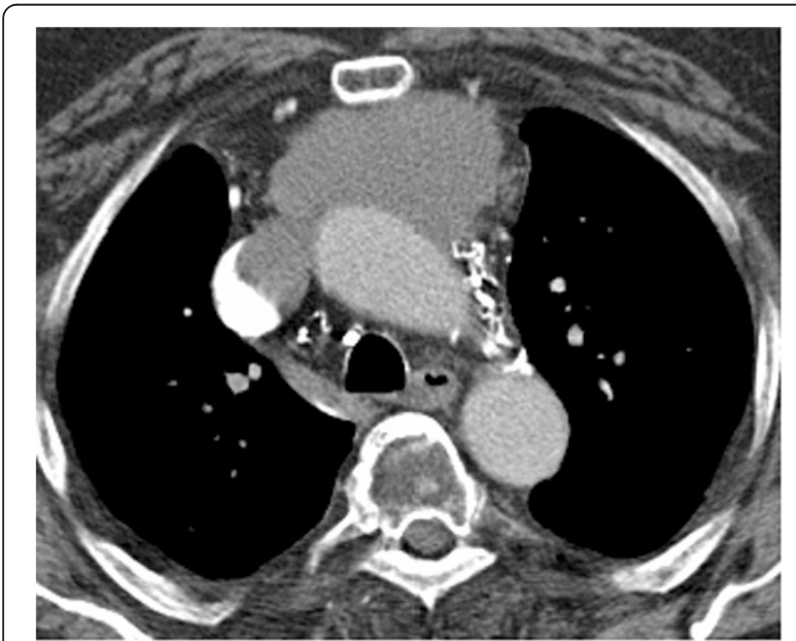

Fig. 1 Thymoma Masaoka-stage III (WHO A) with infiltration of SCV and the right atrium with obstruction. Complete macroscopic resection (RO) with resection of the SCV and reconstruction with Dacron-prosthesis under CPB support (cannulation of the ascending aorta and the femoral vein) of the thymoma, along with the thymic gland, perithymic fat tissue, mediastinal pleura, and pericardium. When appropriate, the resection was extended to the lungs, phrenic nerves (unilateral) and the chest wall. In two patients with additional pleural tumor involvement left-sided radical pleurectomy with resection of the upper lobe or right-sided extrapleural pneumonectomy due to distinctive pulmonary tumor infiltration were performed. Reconstructions of the pericardium or the diaphragm were performed with bovine patches. The resected SCV was replaced by a ring-augmented PTFEprosthesis (Polytetrafluorethylene; $n=1$ ), whereas the LBV was either replaced (PTFE-prosthesis: $n=3$ ) or closed $(n=3)$. One patient with suspicious mediastinal thymoma recurrence underwent re-sternotomy and showed intraoperative tumor infiltration in the ascending aorta, which was resected and reconstructed with a dacron-prosthesis (Hemashield vascular prosthesis $28 \mathrm{~mm}$ ). Final histology ensured only scarred tissue without evidence of recurrent thymoma. A second patient had an invasive thymic carcinoma invading the aortic arch with complete immured supraaortic branches (Fig. 2). The aortic arch was replaced with a Hemashield vascular prosthesis $(22 \mathrm{~mm})$ under hypothermic circulatory arrest (42 $\mathrm{min}$ ) with selective, antegrade cerebral perfusion. Additionally, the brachiocephalic trunk $(8 \mathrm{~mm})$, the left carotid artery $(6 \mathrm{~mm})$ and the left subclavian artery $(6 \mathrm{~mm})$ were reconstructed with vascular prostheses and connected to the aortic arch prosthesis (Fig. 3). Histological examination confirmed a thymic carcinoma 


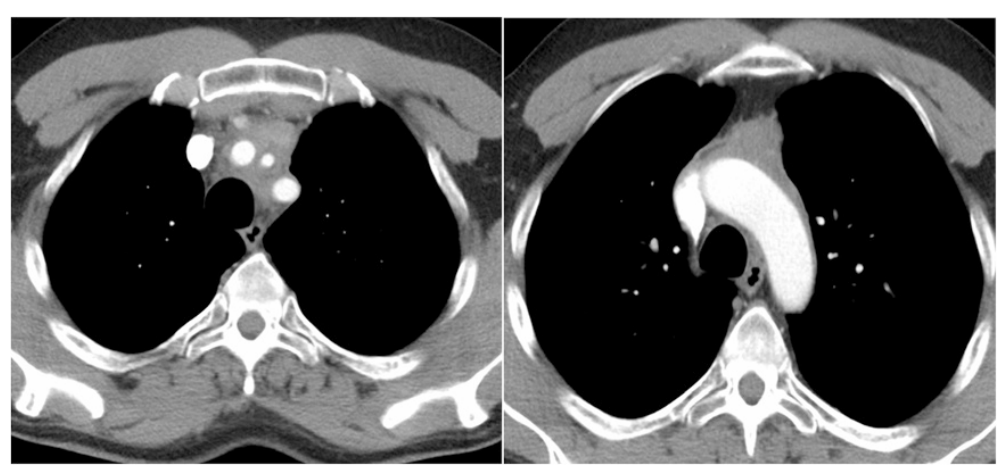

Fig. 2 CT-scan of patient no. 5 with thymic carcinoma (WHO C) encircling the supraaortic branches and with suspicious invasion of the aortic arch

(WHO type C) with invasion into the aortic wall, the brachiocephalic trunk, left carotid artery and the left subclavian artery, which has been completely resected (R0).

A complete tumor resection (R0) was achieved in four (66.6 \%) patients. A microscopic or macroscopic incomplete tumor resection was performed in two patients, due to tumor infiltration of the aortic arch $(\mathrm{R} 1: n=1)$ or the aortic arch, the main pulmonary artery and the myocardium of the left ventricle ( $2: n=1)$.

\section{Postoperative data}

Postoperative data are shown in Table 2. There was no in-hospital mortality or death within 30 days after operation in this series. Severe postoperative complications requiring soon operative revision were observed in half of the patients (50\%). Two patients with a hematothorax underwent successful operative revision. On the third postoperative day, in one patient after extended reconstruction of the aortic arch left-sided chylothorax was diagnosed and the patient underwent successful



Fig. 3 Intraoperative view (patient no. 5) after radical resection of the thymic carcinoma and vascular reconstruction of the aortic arch and the outgoing branches surgical revision. The postoperative course was prolonged and complicated by severe pneumonia with respiratory insufficiency and the need for tracheotomy. The patient has been discharged in a peripheral hospital 47 days after surgery. We disclaimed postoperative mediastinal radiation therapy because of the reduced overall condition of the patient.

Every patient developed a postoperative respiratory insufficiency with the need for reintubation with prolonged mechanical ventilation followed by tracheotomy $(n=5)$. Despite there was no evidence of recurrent thymoma and the patient has been free of symptoms of his myasthenia gravis over one year, the patient developed in the early postoperative period a symptomatic myasthenic crisis combined with a pronounced pneumonia of the left lower lobe. The patient could be successfully treated with intravenous pyridostigmin and non-invasive ventilation $(n=1)$. Postoperative renal insufficiency with temporary renal replacement therapy was necessary in three (50 \%) patients. The median length of stay on the intensive care unit (ICU) was 26 days (range: 5 to 28 days). Except for one patient (discharge home from hospital after 31 days) all patients were directly transferred from the ICU to a peripheral hospital or rehabilitation clinic.

Adjuvant radiotherapy was administered in one patient with acceptable good postoperative clinical conditions after R1-resection. In the other patients no further adjuvant therapy was recommended because of their impaired clinical overall condition after a prolonged postoperative course. At the end of the study in June 2015, $83 \%$ (5/6) patients were alive without evidence of recurrence after a mean follow-up of 20.5 months (range: 7 to 55 months). One patient died 7 months after surgery due to further tumor progress after an incomplete tumor resection (R2). The functional outcome of the patients was good. 
Table 2 Postoperative and follow-up data

\begin{tabular}{|c|c|c|c|c|c|}
\hline Pt & T [20]/UICC & Extent of resection/Residual disease & Postoperative complications & Progress/Recurrence [months] & $\begin{array}{l}\text { Status/Survival } \\
\text { [months] }^{\text {a }} \\
\end{array}$ \\
\hline 1 & $3 / 111 \mathrm{a}$ & Ro/none & $\begin{array}{l}\text { Apoplex, respiratory insufficiency, } \\
\text { tracheotomy }\end{array}$ & None & NED/55 \\
\hline 2 & 4/IIIb & R1/aortic arch & $\begin{array}{l}\text { Pneumonia, respiratory insufficiency, } \\
\text { wound healing disorder }\end{array}$ & $\begin{array}{l}\text { Thymoma metastasis above left } \\
\text { diaphragm, pleural empyema: } \\
\text { complete resection (RO), decortication }\end{array}$ & NED/20 \\
\hline 3 & 4/IIIb & $\begin{array}{l}\text { R2/aortic arch, main pulmonary } \\
\text { artery, myocardium }\end{array}$ & $\begin{array}{l}\text { Pneumonia, respiratory insufficiency, } \\
\text { tracheotomy }\end{array}$ & Mediastinal tumor progress & $\mathrm{DOD} / 7$ \\
\hline 4 & 3/IIla & Ro/none & $\begin{array}{l}\text { Pneumonia, respiratory insufficiency, } \\
\text { tracheotomy }\end{array}$ & None & NED/25 \\
\hline 5 & $4 / I I \mid \mathrm{b}$ & Ro/none & $\begin{array}{l}\text { Pneumonia, respiratory insufficiency, } \\
\text { tracheotomy, gastrointestinal bleeding }\end{array}$ & None & $\mathrm{NED} / 8$ \\
\hline 6 & 4/IIIb & Ro/none & $\begin{array}{l}\text { Pneumonia, respiratory insufficiency, } \\
\text { myasthenic crisis }\end{array}$ & None & $\mathrm{NED} / 8$ \\
\hline
\end{tabular}

UICC Union for International Cancer Control, $T$ T-category, $R O$ no residual tumor, $R 1$ microscopic residual tumor, $R 2$ macroscopic residual tumor, $C T$ chemotherapy, $R T$ radiotherapy, NED no evidence of disease, $D O D$ dead of disease

${ }^{a}$ Follow-up: June 2015

\section{Discussion}

The prognosis of thymoma and thymic carcinoma depends on resection status, tumor stage, until now classified by the Masaoka-Koga staging system which describes the anatomic invasion into surrounding mediastinal structures or the pleural cavity, and, at least in most studies, on WHO-based histology $[3-5,18,19]$. Recently, there is a proposed tumor, node, metastasis (TNM)-based system, which should be applicable to all types of thymic epithelial malignancies [20]. In addition, complete surgical resection is still the most important determinant of survival in these patients $[2,7,21,22]$. Especially in patients with advanced thymoma, surgical resection should be part of a multimodality therapy including chemotherapy and in some cases adjuvant radiotherapy to decrease the risk of recurrence and improve survival $[8,9,23-25]$.

Nevertheless, malignant thymic tumors invading the heart or great vessels are rarely considered for surgical resection with curative intention [13]. In the literature there is only limited data about radical surgical interventions with CPB support presenting only case reports or case series with small numbers of patients [14-17]. In our series we describe six patients, who underwent radical surgical tumor resection with CPB support due to tumor invasion into the heart or great vessels. All patients were carefully selected for this aggressive therapy after multidisciplinary evaluation and proven operability. Finally, this therapy should be at least considered in patients who have no further therapeutic alternatives and only in experienced thoracic surgical centres [13].

Induction therapy is recommended in locally advanced thymomas not eligible for immediate resection [10]. In particular, patients presenting with a large, locally advanced thymoma that is likely to invade adjacent intrathoracic organs, induction chemotherapy is utilized to increase resectability with an objective response rate of approximately $50 \%$ after platin-based combination chemotherapy [6]. Five (83 \%) of our patients received induction chemotherapy with according to the PAC regime or, if octreotid-positive, with octreotid/prednisone to ensure better resectability. In all five patients a partial remission (positive response rate) was observed after reevaluation with computed tomography scans. Although, we only included locally advanced mediastinal tumors with potential invasion of the heart or great vessels, our rate of a macroscopic complete resection with removal of all visible tumor masses was approximately $83 \%$. Tumor debulking surgery (R2) was performed in one patient with massive thymic carcinoma invasion. In our experience and to our knowledge in the literature, no curative, complete resection of invasive thymic malignancies is possible, if there is preoperative suspicion or intraoperative evidence of tumor infiltration in the myocardium of the right/left ventricle. However, this situation should not primarly be a contraindication for surgery, because tumor debulking surgery combined with chemotherapy and radiotherapy is known to improve survival in these patients $[1,12]$.

Great vessel reconstruction can be performed with prosthetic material if there is an extensive tumor invasion of the chest wall [13]. The prosthetic graft patency rates in the left innominate vein position were disappointing $(0 \%)$ and in the future we might just ligate the vein. Complete reconstruction of the aortic arch under antegrade cerebral perfusion was performed in one patient (male, 48 years) with an invasive thymic carcinoma as previously described by Fujino et al. [14].

All of our patients $(100 \%)$ developed postoperative respiratory insufficiency related to pneumonia and also 
suffered from a systemic inflammatory response syndrome (SIRS). These complications might be triggered by the usage of the CPB in tumor patients with already preoperative immunodeficiency related to their malignant disease followed by induction chemotherapy and extended surgical resections of their malignant tumors. In addition to the postoperative intensive care treatment, these patients might benefit from prophylactic, perioperative intravenous antibiotic therapy and additional treatment with immunoglobulines, when appropriate. Furthermore, thymoma patients could develop postoperative paraneoplastic syndromes including myasthenic crisis irrespective of their preoperative neurological condition and medication.

Our current overall calculated median survival rate at the end of the study period in June 2015 was 23 months with five patients being alive without evidence of disease or tumor recurrence. In our department, adjuvant radiotherapy is used in patients with incomplete macroscopic (R2) or microscopic (R1) resection and patients with higher histologic thymoma stages or thymic carcinoma. In this series, only one patient developed adjuvant radiotherapy.

Finally, to our knowledge and experience, the risk of systemic dissemination of tumor cells during CPB seems to be acceptable and lower compared to the risk of haematogenic tumor cell dissemination caused by the vessels invasion of the malignant thymoma or thymic carcinoma.

We are aware of the potential restrictions of our study. The obvious limitation is its observational nature with only a small sample size including six patients without any control group. Nevertheless, we could demonstrate representative patients with large invasive thymoma or thymic carcinoma who underwent radical surgical tumor resection under $\mathrm{CPB}$ support.

\section{Conclusions}

In conclusion, extensive surgical resections of advanced thymoma/thymic carcinoma infiltrating the heart or great vessels with $\mathrm{CPB}$ support are technical feasible in selected patients, but with a significant increased postoperative morbidity. Great vessel infiltration or infiltration of the right atrium should not primarily be a contraindication for surgery. CPB support enables complete tumor resection in selected patients and might lead to a better palliation and a potential for cure with prolonged survival. Surgical resection should always be performed as part of a multimodality therapy in this selected group of patients and only in experienced thoracic surgical departments.

\section{Competing interest}

There is no conflict of interest and nothing to disclose.

\section{Authors' contributions}

MR made substantial contributions to the design of this study, acquisition of data, data analysis and interpretation of data. MR wrote and revised the manuscript. RN, BS, MvS-S, ZS, HH-S participated in the design of this study and have been involved in revising the manuscript critically for important intellectual content. HS has given final approval of the version to be published. All authors read and approved the final manuscript.

\section{Author details}

1Department of Thoracic Surgery, University Medical Center Regensburg, Franz-Josef-Strauß-Allee 11, D-93053 Regensburg, Germany. '2Department of Neurology, University Regensburg at the District Medical Center, Regensburg, Germany. ${ }^{3}$ Department of Thoracic Surgery, Hospital Barmherzige Brüder Regensburg, Regensburg, Germany.

Received: 11 March 2015 Accepted: 27 October 2015

Published online: 29 October 2015

\section{References}

1. Detterbeck FC, Parson AM. Thymic tumors. Ann Thorac Surg. 2004;77:1860-9.

2. Rea F, Marulli G, Girardi R, Bortolotti L, Favaretto A, Galligioni A, et al. Long-term survival and prognostic factors in thymic epithelial tumours. Eur J Cardiothorac Surg. 2004;26:412-8.

3. Masaoka A, Monden Y, Nakahara K, Tanioka T. Follow-up study of thymomas with special reference to their clinical stages. Cancer. 1981;48:2485-92.

4. Koga K, Matsuno Y, Noguchi M, Mukai K, Asamura H, Goya T, et al. A review of 79 thymomas: modification of staging system and reappraisal of conventional division into invasive and non-invasive thymoma. Pathol Int. 1994;44(5):359-67.

5. Rosai J, Sobin L. Histological typing of tumours of the thymus. In: World Health Organization, ed. International histological classification of tumours. Heidelberg: Springer; 1999. p. 1-16.

6. Wright CD. Extended resections for thymic malignancies. J Thorac Oncol 2010;5:344-7. doi:10.1097/JTO.0b013e3181f20eb3.

7. Cardillo G, Carleo F, Giunti R, Lopergolo MG, Salvadori L, De Massimi AR, et al. Predictors of survival in patients with locally advanced thymoma and thymic carcinoma (Masaoka stages III and IVa). Eur J Cardiothorac Surg. 2010;37:819-23.

8. Marulli G, Lucchi M, Margaritora S, Cardillo G, Mussi A, Cusumano G, et al. Surgical treatment of stage III thymic tumors: a multi-institutional review from four Italian centers. Eur J Cardiothorac Surg. 2011;39(3):1-7.

9. Lucchi M, Ambrogi MC, Duranti L, Basolo F, Fontanini G, Angeletti CA, et al. Advanced stage thymomas and thymic carcinomas: results of multimodality treatments. Ann Thorac Surg. 2005;79(6):1840-4.

10. Spaggiari L, Casiraghi M, Guarize J. Multidisciplinary treatment of malignant thymoma. Curr Opin Oncol. 2012;24:117-22.

11. Wright CD. Pleuropneumonectomy for the treatment of Masaoka stage IVA thymoma. Ann Thorac Surg. 2006;82:1234-9.

12. Venuta F, Anile M, Diso D, Vitolo D, Rendina EA, De Giacomo T, et al Thymoma and thymic carcinoma. Eur J Cardiothorac Surg. 2010;37:13-25.

13. Park BJ, Bacchetta M, Bains MS, Downey RJ, Flores R, Rusch WW, et al. Surgical management of thoracic malignancies invading the heart or great vessels. Ann Thorac Surg. 2004;78(3):1024-30.

14. Fujino S, Tezuka N, Watarida S, Katsuyama K, Inoue S, Mori A. Reconstruction of the aortic arch in invasive thymoma under retrograde cerebral perfusion. Ann Thorac Surg. 1998;66(1):263-4.

15. Sakuragi T, Rikitake K, Nastuaki M, Itoh T. Complete resection of recurrent thymic carcinoid using cardiopulmonary bypass. Eur J Cardiothorac Surg. 2002;21(1):152-4

16. Funakoshi $Y$, Ohta M, Maeda H, Matsuda H. Complete resection of recurrent thymic carcinoid using cardiopulmonary bypass. Eur J Cardiothorac Surg. 2003;24(2):331-3

17. Soon JL, Poopalalingam R, Lim CH, Koong HN, Agasthian T. Peripheral cardiopulmonary bypass-assisted thymoma resection. J Cardiothorac Vasc Anesth. 2007;21(6):867-9.

18. Detterbeck FC, Nicholson AG, Kondo K, Van Schil P, Moran C. The MasaokaKoga stage classification for thymic malignancies: clarification and definition of terms. J Thorac Oncol. 2011;6:1710-6.

19. Marx A, Ströbel P, Badve SS, Chalabreysse L, Chan JK, Chen G, et al. ITMIG consensus statement on the use of the WHO histological classification of 
thymoma and thymic carcinoma: refined definitions, histological criteria, and reporting. J Thorac Oncol. 2014;9(5):596-611.

20. Detterbeck FC, Stratton K, Giroux D, Asamura H, Crowley J, Falkson C, et al. The IASLC/ITMIG thymic epithelial tumors staging project: Proposal for an evidence-based stage classification-system for the forthcoming (8th) edition of the TNM classification of malignant tumors. J Thorac Oncol. 2014;9:65-72.

21. Ruffini E, Van Raemdonck D, Detterbeck F, Rocco G, Thomas P, Venuta F. Management of thymic tumors: a survey of current practice among members of the European Society of Thoracic Surgeons. J Thorac Oncol. 2011;6(3):614-23.

22. Ruffini E, Detterbeck F, Van Raemdonck D, Rocco G, Thomas P, Weder W, et al. Thymic carcinoma: a cohort study of patients from the European society of thoracic surgeons database. J Thorac Oncol. 2014;9(4):541-8.

23. Rajan A, Giaccone G. Treatment of advanced thymoma and thymic carcinoma. Curr Treat Options Oncol. 2008;9:277-87.

24. Utsumi T, Shiono H, Matsumura A, Maeda H, Ohta M, Tada H, et al. Stage II thymoma: relationship of local invasion to recurrence. J Thorac Cardiovasc Surg. 2008;136(6):1481-5.

25. Ried M, Potzger T, Braune N, Neu R, Zausig Y, Schalke B, et al. Cytoreductive surgery and hyperthermic intrathoracic chemotherapy perfusion for malignant pleural tumors: perioperative management and clinical experience. Eur J Cardiothorac Surg. 2013;43(4):801-7.

\section{Submit your next manuscript to BioMed Central and take full advantage of:}

- Convenient online submission

- Thorough peer review

- No space constraints or color figure charges

- Immediate publication on acceptance

- Inclusion in PubMed, CAS, Scopus and Google Scholar

- Research which is freely available for redistribution 